\title{
CARACTERIZAÇÃO DE CONCREÇÕES FERRO-MANGANOSAS DE SOLOS DE CALCÁRIO NO NORTE DO ESTADO DE MINAS GERAIS ${ }^{(1)}$
}

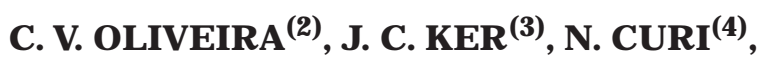 \\ M. N. DUARTE ${ }^{(5)} \&$ L. E. F. FONTES $S^{(3)}$
}

\begin{abstract}
RESUMO
As concreções ferro-manganosas, variáveis quanto ao diâmetro e formato, são comuns em solos desenvolvidos de calcário no norte de Minas Gerais. Normalmente, tendem a aumentar de tamanho com a profundidade nos Cambissolos e Vertissolos e a permanecer pequenas nos Latossolos, onde são mais lisas (menos corroídas) e mais arredondadas (lembrando chumbinho de caça). Com o objetivo de estudá-las, foram coletadas concreções (C) nos horizontes B de Latossolos Vermelhos; B e BC de Cambissolo e C de Vertissolo, agrupadas de acordo com o diâmetro médio $\left(C 1-\phi=0,18 \mathrm{~cm} ; \mathrm{C2}_{-}-\phi=0,53 \mathrm{~cm}\right.$; $C 3-\phi=0,90 \mathrm{~cm} ; C 4-\phi=1,75 \mathrm{~cm})$, sendo $C 1$ as concreções dos Latossolos e C2, C3 e C4 separações das concreções do Cambissolo e do Vertissolo. Tais concreções, após trituradas, foram caracterizadas química (extração de Fe e Mn com oxalatoe DCB; ataque sulfúrico e ataque triácido) e mi neralogicamente (difração de raios$\mathrm{X}$ ). Também foram coletadas amostras indeformadas dos solos que apresentavam concreções, as quais foram impregnadas para análise micromorfológica. A caracterização química das concreções revelou o ferro, a sílica e o manganês como os princi pais constituintes. Houve correlação significativa en negativa entre o diâmetro das concreções e o teor de ferro $(r=-0,88)$, o que concorda com a literatura, bem como mai or acúmulo de ferro nas concreções de menor diâmetro. Também houve correlação positiva entre o diâmetro e o teor de sílica $(r=0,96)$, fato explicado pelos teores de sílica encontrados nos solos e horizontes onde as concreções ocorrem. Para o manganês nenhuma correlação foi observada, o que
\end{abstract}

(1) Trabal ho extraído da Tese de Doutorado da primeira autora, financiado pela FAPEMIG e apresentado no XXVII CBCS. Recebido para publicação em abril de 2000 e aprovado em fevereiro de 2001.

(2) Professora do Departamento de Geografia, Universidade Federal de Minas Gerais - UFMG. Av. Antônio Carlos 6627, CEP 31270090 Belo Horizonte (MG). E-mail: cristian@igc.ufmg.br

(3) Professor do Departamento de Solos, Universidade Federal de Viçosa - UFV. Av. P.H. Rolfs s/n, CEP $36571-000$ Viçosa (MG).

(4) Professor Titular do Departamento de Ciência do Solo, Universidade Federal de Lavras - UFLA. CEP $37200-000$ Lavras (MG).

(5) ${ }^{\text {t }}$ Pesquisadora do Centro Nacional de Pesquisa de Solos da EMBRAPA, Rua J ardim Botânico 1024, J ardim Botânico, CEP 22460000 Rio de J aneiro (RJ). 
contradiz dados de literatura, que revelam normalmente aumento do teor de manganês com o diâmetro. Observou-se, ainda, nas concreções, alguns elementos traços (Ba, $\mathrm{Co}, \mathrm{Ni}, \mathrm{Pb})$. A quantificação de elementos traços demonstrou el evadas concentrações de manganês, com valores médi os 40 vezes maiores que os encontrados nos solos, valores elevados de bário (em média 20 vezes maiores que nos solos) e que tendem a acompanhar o manganês $(r=0,99)$, o que também foi verificado para o Co $(r=0,99), \mathrm{Ni}(r=0,94), \mathrm{Pb}(r=$ 0,99). A difração de raios- $X$ revelou a presença de goethita como único óxido de ferro presente. Também foi detectada a presença de quartzo, caulinita, lithiophorita e traços de minerais 2:1 (possivelmente interestratificados ilita/ esmectita). A micromorfologia revelou a presença de concreções (com organização i nterna concêntrica) e de nódul os ferro-manganosos. Observando do centro para a periferia, as camadas concêntricas das concreções variaram do preto ao amarelo-avermelhado, evidenciando a contribuição do manganês e a possível transformação dos óxidos de ferro, talvez de hematita para goethita. Alguns fragmentos de concreções presentes nos solos encontravam-se recapeados por novos aportes de ferro, indicando que o processo de difusão e concentração do ferro continuava ativo.

Termos de indexação: química, mineralogia e micromorfologia de nódulos e concreções-Fe, Mn, potencial redox, elementos traços, calcário Bambuí.

\section{SUMMARY: CHARACTERIZATION OF IRON-MANGANESE CONCRETIONS OF LIMESTONE-DERIVED SOILS FROM NORTHERN MINAS GERAIS}

The occurrence of iron-manganese concretions, which vary in diameter and shape, are common in limestonederived soils from northern Minas Gerais, Brazil. Normally, they tend to increasetheir sizewith depth in Cambi sols (I ncepti sols) and Verti sols, and to remain small in Latosols (Oxisols), wherethey are smoother and more rounded. Aiming to study them, concretions in the B horizons of Red Latosols, B and BC horizons of Cambisols and $C$ horizons of Vertisol s werecollected and grouped according totheir average diameter ( $\mathrm{C} 1-\mathrm{f}=0.18 \mathrm{~cm} ; \mathrm{C} 2-\mathrm{f}=0.53 \mathrm{~cm} ; \mathrm{C} 3-\mathrm{f}=0.90 \mathrm{~cm} ; \mathrm{C} 4-\mathrm{f}=1.75 \mathrm{~cm}) . \mathrm{Cl}$ areconcretions of Latosols and C2, C3, C4 groups of concretions of Cambisol and Vertisol; after being grinded, they were chemically (Fe and $\mathrm{Mn}$ extracted by oxalate and dithionite (CBD); sulfuric acid digestion and triacid acid digestion) and mineralogi cally (X-ray diffraction) analyzed. Undisturbed samples of soils that had concretions were collected and impregnated for micromorphol ogical analyses. Thechemical characterization of concretions reveal ed that $\mathrm{Fe}, \mathrm{Si}$, and $\mathrm{Mn}$ arethemain components. Therewas a significant and negative correlation between the concretions' diameter and iron amount $(r=-0.88)$, which agrees with theliteratureand indicates higher Feaccumulati on in smaller diameter concretions. Also, there was a significant and positive correlation between the concretions' diameter and silica content $(r=0.96)$, explained by different silica contents of soils and horizons wheretheconcretions occurred. For $\mathrm{Mn}$, no correlation was found, which is not in agreement with theliterature, which commonly postulates that, as thediameter increases, thereis an increment of $\mathrm{Mn}$ amount. Thequantification of traceelements showed, - besides theel evated $\mathrm{Mn}$ amounts, with average val ues 40 times higher than those found in soils - el evated $\mathrm{Ba}$ values (in average 20 times higher than those found in soils) which tend to follow that of $\mathrm{Mn}(r=0.99)$, which was al so verified for $\mathrm{Co}(r=0.99), \mathrm{Ni}(r=0.94)$ and $\mathrm{Pb}(r=0.99)$. Xray diffraction revealed goethite as the sole iron oxide mineral. Quartz, caulinite, lithi phioriteand trace of 2:1 minerals (probably illite/ smectite interstratified) wereal so detected. Micromorphol ogi cal analyses reveal ed the presence of true concretions (having concentric internal organization) and iron-manganese nodules. From the center to the borders, the concentric layers of concretions varied from black to reddish-yel low colors, suggesting $\mathrm{Mn}$ contribution and possible transformation of Feoxides, possibly hematite to goethite Somefragments of concreti ons present in soi Is arecl oaked by new Feadditions, indicating that the process of Fediffusion and concentration is still active

Index terms: Fe, Mn nodules and concretions chemistry, mi neralogy and micromorphol ogy, redox potential, trace elements, Bambuí limestone 


\section{INTRODUÇÃO}

O ferro e o manganês são elementos comuns nos solos e essenciais ao desenvolvimento das plantas. Depois do nitrogênio, são os elementos mais sensíveis às variações das condições redox (Khan \& Fenton, 1996), quando, em condições redutoras (drenagem mais restrita), tornam-se mais solúveis e, portanto, mais móveis, tendendo a acumular-se na forma de mosqueados, nódulos e, ou, concreções (Schwertmann \& Fanning, 1976).

Como a redução é um processo microbiológico, acumulações de ferro e, ou, manganês em sistemas naturais têm sido explicadas por variações de potencial de oxirredução (Eh), pH e atividade microbiana (Sanz et al., 1996).

Presentes na forma reduzida, os íons $\mathrm{Fe}^{2+} \mathrm{eMn}^{2+}$ são solúveis e passam a movimentar-sefacilmente no sistema; parte destes íons é perdida junto à solução do solo via lixiviação, mas parte deles reprecipita na forma de óxidos, em locais onde a oxigenação é mai or, ou no sol o como um todo, quando as condições passam de redutoras a oxidantes. A continuidade desta preci pitação leva à formação das concreções.

As concreções formadas em solos não são iguais, pois elas diferem quanto à forma, tamanho, cor, composição, etc. Diferenças marcantes podem existir noteor ena distribuição deFee Mn entre concreções, mesmo dentro de um perfil de solo (Schwertmann \& Fanning, 1976).

O teor demanganêsé, de forma geral, diretamente relacionado com o tamanho da concreção (Phillippe et al., 1972; Schwertmann \& Fanning, 1976; Uzochukwu \& Dixon, 1986; Sullivan \& Koppi, 1992; Khan \& Fenton, 1996; White \& Dixon, 1996; Sanz et al., 1996), enquanto o de ferro é inversamente relacionado com o tamanho, mas de forma menos consistente. Como exemplo, pode-se citar o estudo de nódulos de ferro e manganês em ambientes semiáridos, realizado por Sanz et al. (1996), que não encontraram relação entre o tamanho dos nódul os e o teor de ferro.

Zhang \& Karathanasis (1997), analisando concreç̃óes de ferro e manganês em Alfissolos dos EUA, revelaram que tanto o teor de manganês quanto o de ferro foram maiores com o aumento do tamanho das concreç̃os. Quanto à profundidade, parece ocorrer, consistentemente, aumento do teor de ferro e manganês, quando se aumenta a profundidade de ocorrência da concreção no perfil do solo (Phillippe et al., 1972).

Além do ferro e do manganês, outros elementos também estão presentes nas concreções; normalmente, estes elementos são geoquimi camente afins a esses componentes das concreções. Minerais pesados são seletivamente fixados pelos óxidos de $\mathrm{Mn}$ presentes nas concreções, principalmente pela sua carga superficial negativa (McKenzie, 1981;
White \& Dixon, 1996). Uzochukwu \& Dixon (1986) observaram que a caracterização química de concreções revel ou que o teor de Mn observado foi similar em magnitude ao teor de ferro. Elementos traços, como Zn, Cu, Ba e Li, eram geralmente muito mais abundantes nas concreções em comparação com a matriz do solo.

Normalmente, percebe-sea presença de goethita, quartzo e de óxidos de manganês variáveis (lithiophorita - Soares, 1980; bi rnessita elithiophorita - Tokashiki et al., 1986; bi rnessita evernadita - Sanz et al., 1996). Noentanto, alguns autores, trabal hando com concreções, observaram ausência de óxidos de manganês, apesar do altoteor desteelemento (Singh \& Gilkes, 1996; Zhang \& Karathanasis, 1997). Segundo Ross J r. et al . (1976), isso pode ser explicado pela presença de compostos de manganês de baixa cristalinidade ou de cristais finamente divididos ou pouco evoluídos e, por isso, amorfos aos raios- $X$.

As concreções ferro-manganosas, variáveis quanto ao diâmetro e formato, são comuns em sol os desenvol vidos de cal cário no norte de Minas Gerais. Normalmente, tendem a aumentar de tamanho com a profundidade nos Cambissolos e Vertissolos e a permanecer pequenas nos Latossol os, onde são mais lisas (menos corroídas) e mais arredondadas (lembrando chumbinho de caça). Considerando a inexistência de informações, este trabal ho teve por objetivo caracterizar química, mineralógica e micromorfologicamente as concreções presentes nestes solos.

\section{MATERIAL E MÉTODOS}

As concreções estudadas foram col etadas no horizonte B eBC deCambissol oHáplicoTa eutrófico, horizonte $\mathrm{Cv}$ de Vertissolo Cromado Carbonático típico, e horizonte Bw de Latossolo Vermelho eutrófico típico e Latossolo Vermel ho distrófico típico (EMBRAPA, 1999), localizados entre o município de J aíba e a sede do Distrito Agroindustrial do J aíba em Mocambinho, norte de Minas Gerais, entre os paralelos $15^{\circ} 07^{\prime}$ e $15^{\circ} 22^{\prime}$ de latitude sul e os meridianos $43^{\circ} 45^{\prime}$ e $43^{\circ} 58^{\prime}$ a oeste de Greenwich, onde a ocorrência de concreções ferro-manganosas variáveis quanto ao diâmetro eformato são comuns.

Normalmente, nos Latossolos, as concreções são pequenas, lisas (menos corroídas) e arredondadas, lembrando chumbinho de caça, sendo bem distribuídas em todo o perfil. No Cambissolo e Vertissolo, são mais rugosas (mais corroídas), maiores que as observadas nos Latossolos e aumentam de tamanho em profundidade.

Depois de col etadas, as concreções foram divididas em quatro grupos de acordo com o diâmetro médio $(C 1-\phi=0,18$ cm; C2- $\phi=0,53 \mathrm{~cm} ; C 3-\phi=0,90 \mathrm{~cm} ; C 4-\phi=$ $1,75 \mathrm{~cm})$, arbitrado conforme o domínio de cada dasse, 
a fim de se obter um valor numérico para análise estatística: sendo C1 - as concreções dos Latossolos eC2, C3eC4 referentes às separações feitas em função do diâmetro, das concreções do Cambissol oeVertissolo.

As concreções foram trituradas e submetidas às seguintes análises químicas: (a) ataque sulfúrico para quantificação de sílica, alumínio, ferro, fósforo, titânio, potássio e manganês - EMBRAPA, 1997); (b) análise química total - realizada pelo ataquetriácido (fluorídrico $(\mathrm{HF})$, perclórico $\left(\mathrm{HClO}_{4}\right)$ e clorídrico $(\mathrm{HCl}))$, quando duplicatas de $0,5 \mathrm{~g}$ das amostras das concreções trituradas foram transferidas para béqueres de teflon e nelas foram adicionados $10 \mathrm{ml}$ de $\mathrm{HF}, 5 \mathrm{ml}$ de $\mathrm{HCl}$ e 2,5 ml de $\mathrm{HClO}_{4}$ concentrados. Em seguida, as amostras foram aquecidas em banhode-areia até à saída de vapores de $\mathrm{HClO}_{4}$. Após resfriamento, foram adicionados mais $10 \mathrm{ml}$ de HF e $5 \mathrm{ml}$ de $\mathrm{HCl}$, com posterior aquecimento atésecura completa, e, em seguida, mais $2,5 \mathrm{ml}$ de $\mathrm{HCl}$ e, novamente, aqueceu-se até secura completa, seguida de adição de $5 \mathrm{ml}$ de $\mathrm{HCl}$ com ligeiro aquecimento, para dissolução dos sais, transferindo-se o extrato para balão de $100 \mathrm{ml}$. Os el ementos maiores (Al, Fe, $\mathrm{P}, \mathrm{Ti}, \mathrm{K}, \mathrm{Ca}, \mathrm{Mg}, \mathrm{Na}$ ) e menores (traços - $\mathrm{Mn}, \mathrm{Ni}, \mathrm{Cr}$, $\mathrm{Co}, \mathrm{Zn}, \mathrm{Mo}, \mathrm{Cu}, \mathrm{Pb}, \mathrm{Cd}$ ) foram determinados por leitura em espectômetro de emissão atômica (plasma). O silício (Si) foi determinado por diferença, descontando-se a perda ao fogo (amostra calcinada a $1.100^{\circ} \mathrm{C}$ por uma hora) e o teor dos outros el ementos, segundo método adotado no laboratório de análises do CPMTC-IGC-UFMG. Amostras de TFSA de horizontes selecionados dos solos de onde foram retiradas as concreções, também foram submetidas ao ataque triácido.

Além das análises mencionadas, foi utilizada a determinação dos teores de ferro e manganês extraídos com DCB (Mehra \& J ackson, 1960) e oxalato ácido de amônio (McK eague \& Day, 1966), por absorção atômica. Após a obtenção dos dados a partir de três repetições de cada análise, foi feito tratamento estatístico (correlação linear simples).

A análise mineralógica consistiu na difração de raios-X das amostras trituradas após tratadas com $\mathrm{NaOH} 5 \mathrm{~mol} \mathrm{~L}^{-1}$ (Kämpf \& Schwertmann (1982), para concentração dos óxi dos e mel hor visualização dos picos característicos. As amostras foram montadas em lâminas escavadas (sem orientação) e irradiadas de 20 a 802 2 , em difratômetro de raios-X (Rigaku Geigerflex), com tubo de cobre e monocromador de grafite. Também foi realizada difração de raios- $X$ das amostras trituradas, após desfer rificação com ditionito-citrato-bicarbonato de sódio (Mehra \& J ackson, 1960).

A caracterização micromorfológica consistiu da observação de amostras indeformadas dos sol os que continham concreções, as quais, após secas em estufa, foram impregnadas com uma mistura de $740 \mathrm{ml}$ de resina poliéster (POLYLITE T-208), $260 \mathrm{ml}$ de estireno, 37 gotas de catalisador e seis gotas de pigmento ultravioleta para um volume final de 1 litro. Após secagem à temperatura ambiente, as amostras foram cortadas, sendo confeccionadas lâminas finas de $6 \times 2 \mathrm{~cm}$, no CPMTC-IGC-UFMG, as quais foram descritas no Laboratório de Solos do Centro Nacional de Pesquisa de Solos (CNPSEMBRAPA), em um fotomicroscópio III petrográfico Zeiss, usandoas terminologias sugeridas por Brewer (1976).

\section{RESULTADOS E DISCUSSÃO}

\section{Cor e análises químicas das concreções}

A cor das concreções, após trituradas (Quadro 1), encontra-se dentro dos matizes 7,5YR e10YR, o que indica o predomínio da goethita em relação à hematita, fato comprovado pela difração de raios- $X$. Os baixos valores de croma das concreções 2 e 3 (Quadro 1) podem estar associados à presença de manganês, que impinge uma col oração mais escura (McKenzie, 1989), o que condiz com os maiores teores deste el emento observados nestas concreções.

A extração de ferro com DCB revel ou a presença de óxidos bastante resistentes à redução nas concreções, pois, após cinco extrações sucessivas, ainda se tem presença do elemento no extrato (Figura 1a).

Quadro 1. Diâmetro médio, limites e cor Munsell das concreções trituradas

\begin{tabular}{cccc}
\hline Concreção & Diâmetro médio & Diâmetro limite & Cor \\
\cline { 2 - 3 } & & $\mathrm{cm}$ & \\
C1 & 0,18 & $0,10-0,25$ & $7,5 Y \mathrm{R} 4 / 6$ (bruno forte) \\
C2 & 0,53 & $0,40-0,70$ & $10 Y \mathrm{R} 3 / 3$ (bruno-escuro) \\
C3 & 0,90 & $0,75-1,10$ & $10 Y \mathrm{R} 4 / 3$ (bruno) \\
C4 & 1,77 & $1,60-2,00$ & $10 Y \mathrm{R} 5 / 6$ (bruno-amarelado) \\
\hline
\end{tabular}



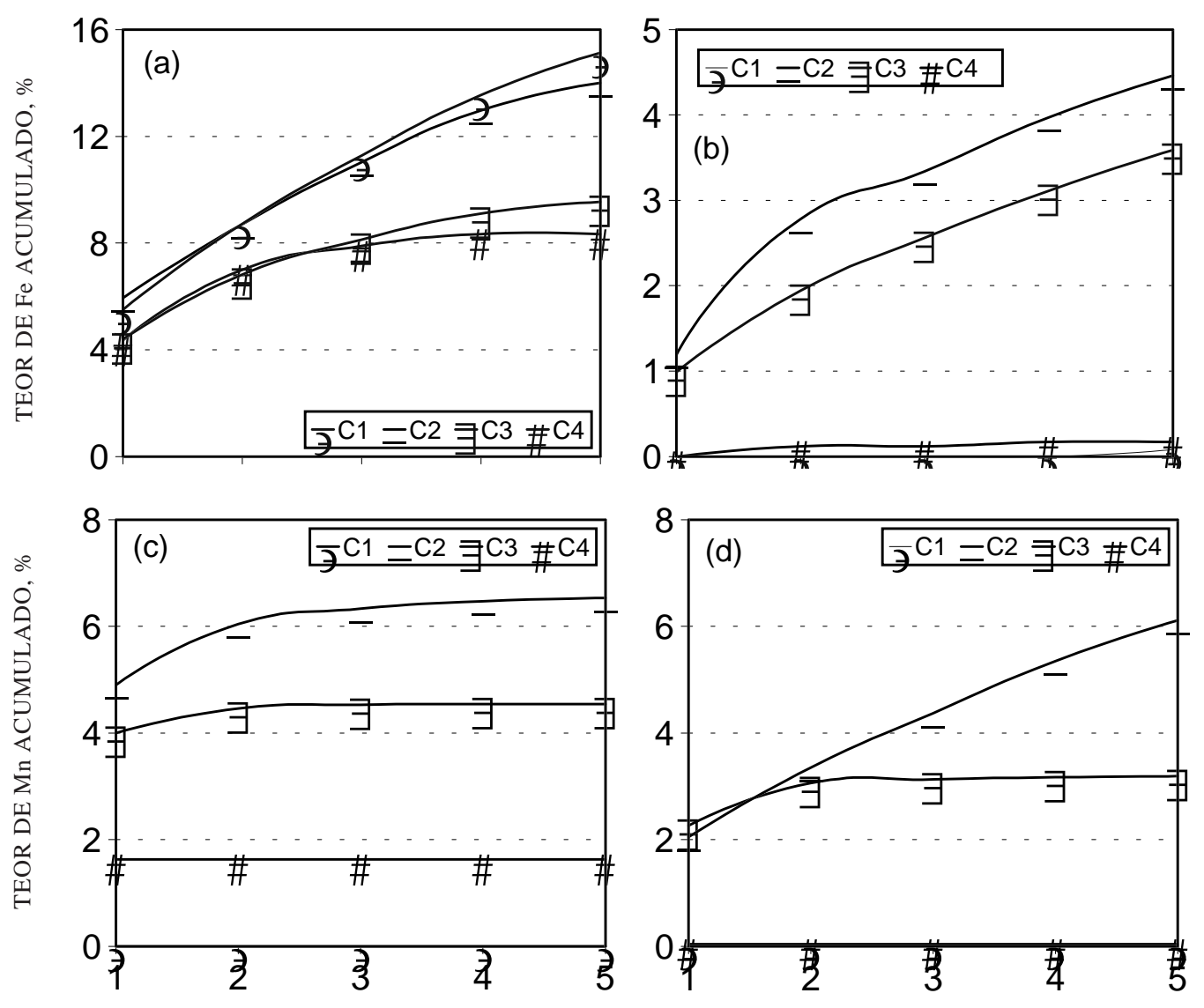

NÚMERO DE EXTRAÇÕES

Figura 1. Curva dos teores de ferro e manganês resultantes de extrações sucessivas com DCB e oxalato das concreções de ferro e manganês. (a) Fe-DCB; (b) Fe-oxalato; (c) Mn-DCB; (d) Mn-oxalato.

Observou-se uma relação inversa entre o diâmetro das concreções e as concentrações de ferro extraídas pelo DCB $(r=-0,92$, a $5 \%)$, fato também constatado pelos resultados do ataque sulfúrico e triácido (Quadro 2), com coeficientes de correlação negativos e significativos a $5 \%(r=-0,95$ no ataque sulfúrico; $r=-0,90$ no ataque triácido). Estas constatações concor dam com dados da literatura, em que é apregoada correlação inversa entre tamanho de concreções e teor de ferro (Phillippe et al., 1972; Schwertmann \& Fanning, 1976; Uzochukwu \& Dixon, 1986; Sullivan \& Koppi, 1992; K han \& Fenton, 1996; White \& Dixon, 1996). A mesma tendência não foi confirmada na extração com oxalato (Figura 1b), o que pode ser explicado pela menor eficiência deste em extrair formas mais cristalinas, não resultando em teores que acompanhem aqueles de extratores mais eficientes.

A relaçãoFeo/Fed, determinada com os resultados da primeira extração com os dois extratores, foi baixa para todas as concreções, indicando presença de pequenas quantidades de minerais de pior cristalinidade, como a ferridrita, fatotambém observado por Ramanai dou et al . (1996) epor Singh \& Gilkes (1996).
A quantificação dos elementos pelo ataque sulfúrico e pelo ataque triácido (Quadro 2) revel ou que as concreções contêm teores el evados de $\mathrm{Fe}_{2} \mathrm{O}_{3}$ e $\mathrm{SiO}_{2}$, sendo o teor de ferro das concreções, em média, quatro vezes maior em relação à média encontrada nos solos.

Quanto à sílica, houve correlação positiva entre o diâmetro e o teor de $\mathrm{SiO}_{2}(r=0,96$ no ataque sulfúrico; $r=0,98$ noataquetriácido). Essa constatação foi diferente dos resultados deZhang \& Karathanasis (1997) sobre concreções de ferro e manganês em Alfissolos dos EUA, onde o teor de $\mathrm{SiO}_{2}$ foi inversamente proporcional aotamanho. Possivel mente, isso se deve, primeiramente, aos solos de onde se originaram as concreções, pois o teor de sílica é bem maior no Cambissol o e no Vertissolo, (onde estão as concreções maiores - C2, C3eC4) doquenos Latossolos (C1) (Quadro3). Além disso, a análisemi cromorfológica dos sol os (Oliveira et al., 2000) revel ou migração de sílica e acumulação em profundidade, no Cambissolo e Vertissol o, o que é condizente com as condições de $\mathrm{pH}$ do meio. Observa-se, ainda, que nas concreções também se concentram outros macroel ementos, além da sílica e do ferro (Quadro 2). 
Quadro 2. Teores de macroelementos resultantes do ataque sulfúrico (S) e do ataque triácido (T) das concreções (C) de ferro e manganês

\begin{tabular}{ccccc}
\hline Identificação & $\mathbf{C 1}$ & $\mathbf{C 2}$ & $\mathbf{C 3}$ & $\mathbf{C 4}$ \\
\hline & \multicolumn{4}{c}{ dag kg $^{-1}$} \\
$\mathrm{SiO}_{2}$ & & \multicolumn{5}{c}{} \\
$\mathrm{S}$ & 14,34 & 18,69 & 20,19 & 23,77 \\
$\mathrm{~T}$ & 24,37 & 35,67 & 37,38 & 52,56 \\
$\mathrm{Al}_{2} \mathrm{O}_{3}$ & & & & \\
$\mathrm{~S}$ & 18,30 & 16,85 & 20,08 & 20,29 \\
$\mathrm{~T}$ & 14,22 & 13,51 & 13,15 & 17,05 \\
$\mathrm{Fe}_{2} \mathrm{O}_{3}$ & & & & \\
$\mathrm{~S}$ & 55,73 & 31,87 & 34,89 & 14,10 \\
$\mathrm{~T}$ & 44,41 & 24,95 & 22,47 & 12,84 \\
$\mathrm{P}_{2} \mathrm{O}_{5}$ & & & & \\
$\mathrm{~S}$ & 0,07 & 0,06 & 0,09 & 0,10 \\
$\mathrm{~T}$ & 0,08 & 0,06 & 0,05 & 0,05 \\
$\mathrm{TiO}_{2}$ & & & & \\
$\mathrm{~S}$ & 0,86 & 0,71 & 0,93 & 0,73 \\
$\mathrm{~T}$ & 0,80 & 0,83 & 0,74 & 1,40 \\
$\mathrm{~K}_{2} \mathrm{O}$ & & & & \\
$\mathrm{S}$ & 0,03 & 0,44 & 0,53 & 0,68 \\
$\mathrm{~T}$ & 0,04 & 0,50 & 0,61 & 0,68 \\
$\mathrm{CaO}$ & & & & \\
$\mathrm{S}$ & 0,29 & 0,60 & 0,84 & 0,31 \\
$\mathrm{~T}$ & 0,14 & 0,52 & 0,66 & 0,17 \\
$\mathrm{MgO}$ & & & & \\
$\mathrm{S}$ & 0,48 & 0,69 & 0,78 & 0,30 \\
$\mathrm{~T}$ & 0,12 & 0,21 & 0,23 & 0,26 \\
$\mathrm{Na} \mathrm{a}_{2} \mathrm{O}$ & & & & \\
$\mathrm{S}$ & 0,02 & 0,02 & 0,03 & 0,10 \\
$\mathrm{~T}$ & 0,07 & 0,08 & 0,07 & 0,06 \\
\hline & & & &
\end{tabular}

Para o manganês, não foi constatada correlação entre o teor do elemento extraído pelo DCB (Figura 1 c) e pelo oxalato (Figura $1 d$ ), em relação ao diâmetro. Isto é contraditório no que se refere às informações de literatura, em que, normalmente, se observam teores crescentes deste elemento com o diâmetro (Phillippe et al., 1972; Schwertmann \& Fanning, 1976; Uzochukwu \& Dixon, 1986; Sullivan \& Koppi, 1992; K han \& Fenton, 1996; White\& Dixon, 1996; Sanz et al., 1996). O mesmo foi constatado para os resultados de ataque sulfúrico ede ataque triácido (Quadro 4). É provável queisso se deva às variações do potencial redox, pois, segundo Phillippe et al., 1972 eWhite \& Dixon, 1996, quando a modificação do potencial redox ocorre de forma brusca, é comum que as concreções engl obem parte da matriz do solo, causando uma diluição rel ativa daquel es el ementos que tendem a predominar, como o caso do $\mathrm{Mn}$. Neste aspecto, pode-se observar (Quadro 4) que há uma tendência do aumento do teor de manganês com o tamanho, considerando as concreções C1, C2 e C3, ou seja, apenas a C4, sujeita a maiores variações do potencial redox por causa de sua localização (ocorrem nos horizontes mais profundos e, conseqüentemente, mais sujeitos a variações de $E h)$, foge a essa tendência.

A quantificação de elementos traços (Quadro 4) demonstrou, também, que, além do ferro e da sílica, o manganês representa parte importante na constituição das concreções, com valores médios 40 vezes maiores que os encontrados nos solos (Quadros 3 e 4). Vale destacar os valores el evados de outros elementos que tendem a acompanhar o manganês, como o Co $(r=0,99), \mathrm{Ni}(r=0,94)$ e $\mathrm{Pb}$ $(r=0,99)$. Isso pode ser explicado pela fixação sel etiva de alguns minerais pesados pel os óxidos de $\mathrm{Mn}$, principalmente pela sua carga superficial negativa (McK enzie, 1981; White \& Dixon, 1996).

Correlações significativas foram também encontradas entre os teores de ferro e os de $\mathrm{Cu}$ $(r=0,99), Z n(r=0,99), \operatorname{Cr}(r=0,99)$, fato explicado pela forte afinidade geoquímica entre estes el ementos (Srivastava \& Gupta, 1996).

\section{Mineralogia e micromorfologia}

Conforme indicado pela cor, a difração de raios- $X$ das amostras tratadas com $\mathrm{NaOH}$ das concreções (Figura 2) revel ou presença de goethita, como o óxido de ferro predominante, o que concorda com vários resultados deliteratura (Tokashiki et al., 1986; Sanz et al., 1996; Zhang \& Karathanasis, 1997). I sso pode ser devido ao ambiente mais hidromórfico que favorece a goethita, dificultando a formação da ferridrita, necessário percursor da hematita. Também foi detectada presença de lithiophorita como o único óxido de manganês e de quartzo. Nas amostras desferrificadas, constatou-se existência de caulinita, quartzo e traços de minerais 2:1 (provavel mente interestratificados ilita/esmectita) (Figura 3).

A micromorfologia revelou a presença de concreções, ou seja, estruturas com organização interna concêntrica, bem como de nódul os de ferro e manganês, os quais têm organização interna ou fábrica indiferenciada (Brewer, 1976) (Figuras 4a,b). Observando do centro para a periferia, as camadas concêntricas das concreções variam do preto ao amarel o-avermel hado, mostrando a contribuição do manganês e os diferentes graus de hidratação do óxido de ferro.

Alguns fragmentos de concreções presentes no Cambissol o e noVertissol o encontram-se recapeados por novos aportes de ferro (Figura 4c), indicando que o processo de difusão e concentração do ferro continua ativo, o quejá era esperado em decorrência do ambiente em que estes sol os se encontram, ainda sujeito a variações do potencial redox. I sso concorda com a afirmação de White \& Dixon (1996) de que, comparando a matrix do solo e as concreções, as 
Quadro 3. Teores de elementos resultantes do ataque triácido de horizontes selecionados dos solos de onde foram retiradas as concreções de ferro e manganês

\begin{tabular}{|c|c|c|c|c|c|c|}
\hline \multirow[t]{3}{*}{ Horizonte } & $\mathrm{SiO}_{2}$ & $\mathbf{A l}_{2} \mathbf{O}_{3}$ & $\mathrm{Fe}_{2} \mathrm{O}_{3}$ & $\mathbf{P}_{2} \mathbf{O}_{5}$ & $\mathrm{TiO}_{2}$ & $\mathrm{~K}_{2} \mathrm{O}$ \\
\hline & \multicolumn{6}{|c|}{ dag kg-1 } \\
\hline & \multicolumn{6}{|c|}{ Vertissolo Cromado carbonático típico } \\
\hline \multirow[t]{2}{*}{ Cv2 } & 46,23 & 22,75 & 10,23 & 0,02 & 1,41 & 1,23 \\
\hline & \multicolumn{6}{|c|}{ Cambissolo Háplico Ta eutrófico } \\
\hline \multirow[t]{2}{*}{$\begin{array}{l}\mathrm{Bi} 2 \\
\mathrm{BCV}\end{array}$} & $\begin{array}{l}58,69 \\
56,82\end{array}$ & $\begin{array}{l}17,29 \\
15,96\end{array}$ & $\begin{array}{r}9,58 \\
11,62\end{array}$ & $\begin{array}{l}0,02 \\
0,02\end{array}$ & $\begin{array}{l}1,01 \\
1,01\end{array}$ & $\begin{array}{l}0,94 \\
0,95\end{array}$ \\
\hline & \multicolumn{6}{|c|}{ Latossolo Vermelho eutrófico típico } \\
\hline \multirow[t]{2}{*}{ Bw2 } & 53,45 & 21,27 & 10,90 & $<0,01$ & 0,84 & 1,30 \\
\hline & \multicolumn{6}{|c|}{ Latossolo Vermelho distrófico típico } \\
\hline \multirow[t]{4}{*}{ Bw2 } & 52,16 & 22,44 & 11,65 & $<0,01$ & 1,01 & 1,56 \\
\hline & $\mathrm{CaO}$ & MgO & $\mathrm{Na}_{2} \mathrm{O}$ & Mn & $\mathbf{N i}$ & $\mathbf{C r}$ \\
\hline & & dag $\mathrm{kg}^{-1}$ & - & 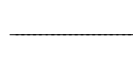 & $\mathrm{kg}^{-1}$ & - \\
\hline & \multicolumn{6}{|c|}{ Vertissolo Cromado carbonático típico } \\
\hline \multirow[t]{2}{*}{ Cv2 } & 1,60 & 0,57 & 0,07 & 1.088 & 54 & 102 \\
\hline & \multicolumn{6}{|c|}{ Cambissolo Háplico Ta eutrófico } \\
\hline \multirow{3}{*}{$\begin{array}{l}\mathrm{Bi} 2 \\
\mathrm{BCV}\end{array}$} & 0,35 & 0,43 & 0,06 & 728 & 41 & 96 \\
\hline & 0,59 & 0,43 & 0,08 & 1.924 & 54 & 95 \\
\hline & \multicolumn{6}{|c|}{ Latossolo Vermelho eutrófico típico } \\
\hline \multirow[t]{2}{*}{ Bw2 } & 0,33 & 0,48 & 0,06 & 1.478 & 70 & 154 \\
\hline & \multicolumn{6}{|c|}{ Latossolo Vermelho distrófico típico } \\
\hline \multirow[t]{3}{*}{ Bw2 } & 0,03 & 0,57 & 0,08 & 1.023 & 66 & 182 \\
\hline & Co & $\mathbf{Z n}$ & Mo & $\mathrm{Cu}$ & $\mathbf{P b}$ & Cd \\
\hline & \multicolumn{6}{|c|}{ Vertissolo Cromado car bonático típico } \\
\hline \multirow[t]{2}{*}{ Cv2 } & 36 & 45 & 217 & 38 & 38 & 2 \\
\hline & \multicolumn{6}{|c|}{ Cambissolo Háplico Ta eutrófico } \\
\hline \multirow{3}{*}{$\begin{array}{l}\mathrm{Bi2} 2 \\
\mathrm{BCv}\end{array}$} & 27 & 33 & 158 & 37 & - & 1 \\
\hline & 41 & 36 & 149 & 30 & 44 & 2 \\
\hline & \multicolumn{6}{|c|}{ Latossolo Ver melho eutrófico típico } \\
\hline \multirow[t]{2}{*}{ Bw2 } & 59 & 34 & 197 & 35 & 74 & 2 \\
\hline & \multicolumn{6}{|c|}{ Latossolo Vermelho distrófico típico } \\
\hline Bw2 & 37 & 33 & 193 & 39 & 46 & 2 \\
\hline
\end{tabular}

últimas funcionam como centro dealto potencial redox dentro de uma matrix redutora. Esta diferença de potencial entre a matrix e as concreções leva a um gradiente de concentração, fazendo com queas formas de Fe e $\mathrm{Mn}$ reduzidas movimentem-se em direção às concreções ondeserão preci pitadas na forma de óxido, o que é chamado de mecanismo de auto-oxidação.
Segundo estes mesmos autores, as concreções, graças à sua baixa porosidade, apresentam resistência à redução, mantendo-se estáveis; no entanto, tal resistência apresenta certos limites, ou seja, se as condições se mantiverem redutoras, com o tempo alcançar-se-á um potencial para reduzir o $\mathrm{Mn}$ e, posteriormente, o Fe. 
Quadro 4. Teores de elementos traços resultantes do ataque sulfúrico (S) e do ataque triácido (T) das concreções de ferro e manganês

\begin{tabular}{|c|c|c|c|c|c|}
\hline \multirow{2}{*}{ Identificação } & \multicolumn{2}{|c|}{ Mn } & \multirow{2}{*}{$\begin{array}{c}\mathbf{N i} \\
\mathbf{T}\end{array}$} & \multirow{2}{*}{$\begin{array}{c}\mathrm{Cr} \\
\mathbf{T}\end{array}$} & \multirow{2}{*}{$\begin{array}{c}\text { Co } \\
\mathbf{T}\end{array}$} \\
\hline & $\mathbf{S}$ & $\mathbf{T}$ & & & \\
\hline & & 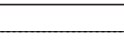 & $\mathrm{g} \mathrm{kg}^{-1}$ & 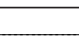 & - \\
\hline \multirow[t]{3}{*}{$\begin{array}{l}\mathrm{C} 1 \\
\mathrm{C} 2 \\
\mathrm{C} 3 \\
\mathrm{C} 4\end{array}$} & $\begin{array}{r}3.134 \\
38.888 \\
39.894 \\
1.770\end{array}$ & $\begin{array}{r}4.120 \\
50.370 \\
52.050 \\
12.830\end{array}$ & $\begin{array}{r}63 \\
123 \\
156 \\
54\end{array}$ & $\begin{array}{r}201 \\
106 \\
83 \\
103\end{array}$ & $\begin{array}{r}72 \\
317 \\
296 \\
120\end{array}$ \\
\hline & Zn & Mo & $\mathrm{Cu}$ & $\mathbf{P b}$ & Cd \\
\hline & \multicolumn{5}{|c|}{$\mathbf{T}$} \\
\hline $\begin{array}{l}\mathrm{C} 1 \\
\mathrm{C} 2 \\
\mathrm{C} 3 \\
\mathrm{C} 4\end{array}$ & $\begin{array}{l}57 \\
49 \\
46 \\
46\end{array}$ & $\begin{array}{l}141 \\
144 \\
152 \\
176\end{array}$ & $\begin{array}{r}129 \\
90 \\
61 \\
66\end{array}$ & $\begin{array}{l}135 \\
839 \\
870 \\
210\end{array}$ & $\begin{array}{r}30 \\
14 \\
13 \\
5\end{array}$ \\
\hline
\end{tabular}

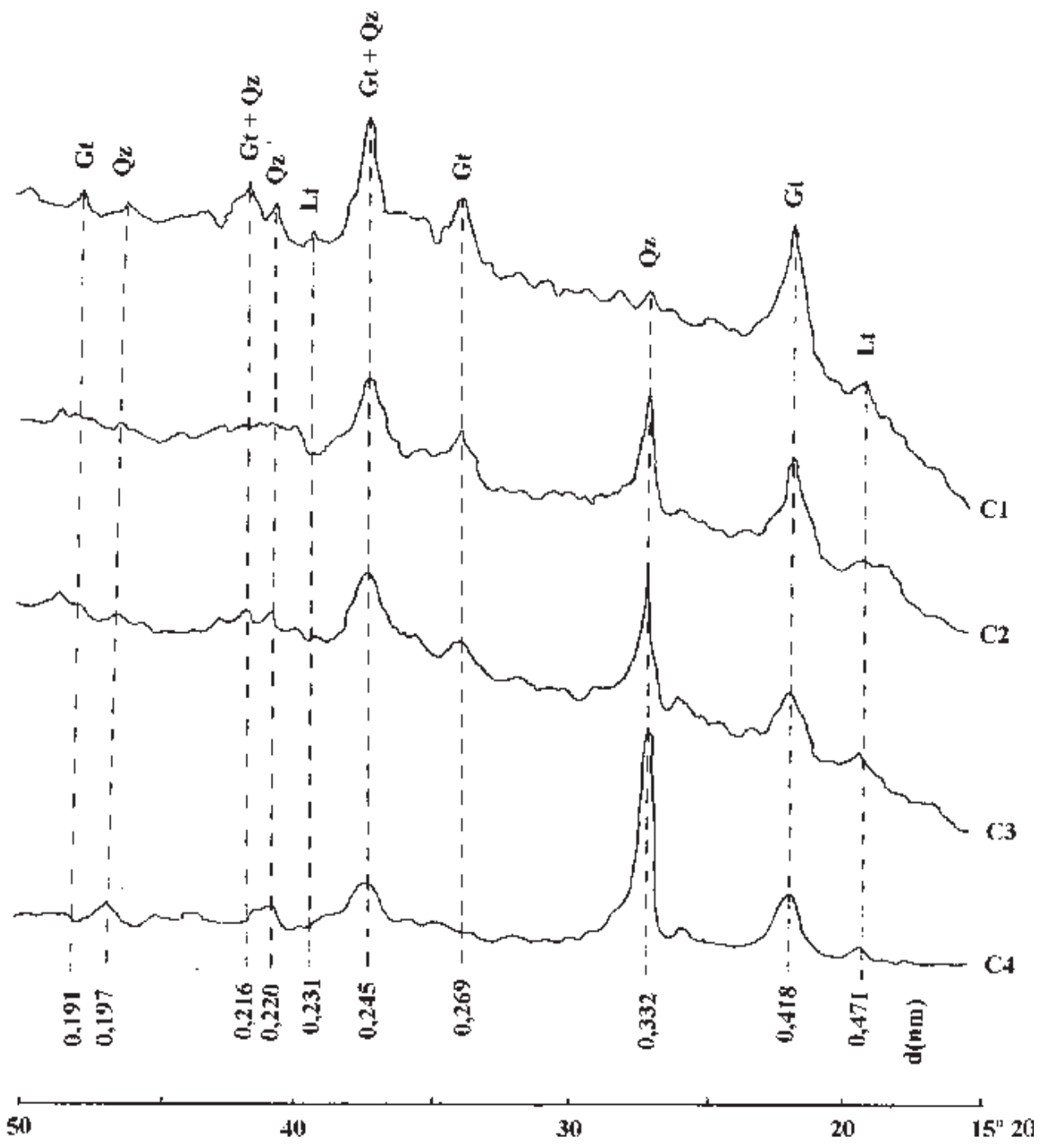

Figura 2. Difratogramas de raios-X das concreções de ferro e manganês trituradas, após concentração de óxidos de ferro (Gt - goethita; Qz - quartzo; Lt - lithiophorita). 


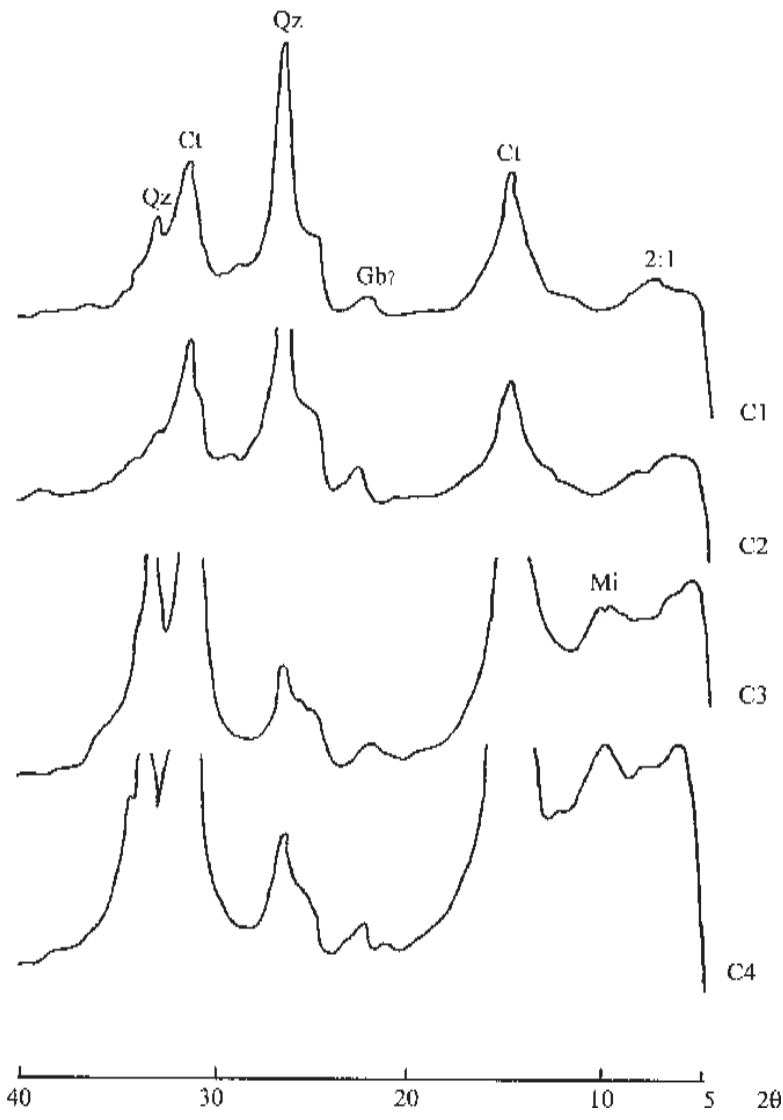

Figura 3. Difratogramas de raios-X das concreções desferrificadas de ferro e manganês trituradas e tratadas com ditionito - citrato - bicarbonato de sódio (Ct - caulinita; Qz - quartzo; Gb gibbsita; Mi - mica e Es - Esmectita).

\section{CONCLUSÕES}

1. As concreções mostraram-se bastante variáveis, tanto em relação ao tamanho como em relação à composição química e à micromorfologia, refletindo diferenças de ambiente de formação, tanto dos sol os quando dos horizontes onde se encontram, principamente no que se refere ao potencial redox.

2. Mineralogicamente, a goethita, a lithiophorita, a caul inita eo quartzo foram os princi pais constituintes revelados pela difratometria de raios- $X$, não apresentando grandes diferenças entre as concreções.

3. A caracterização química das concreções revelou o ferro, a sílica e o manganês como os principais constituintes. Houve correlação significativa e negativa entre o diâmetro das concreções e o teor de ferro, e positiva com o teor de sílica. Para o manganês nenhuma correlação foi observada, o que contradiz dados de literatura.

4. A micromorfologia revelou a existência de concreções e de nódulos. Além disso, no Cambissolo (a)

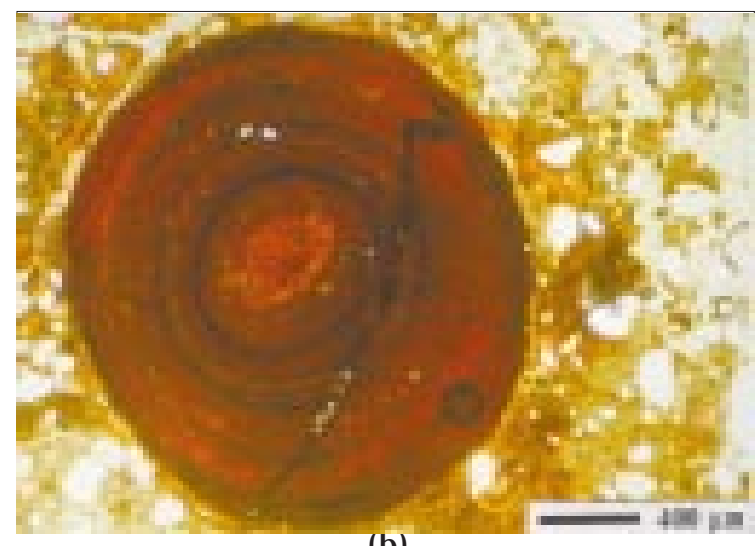

(b)

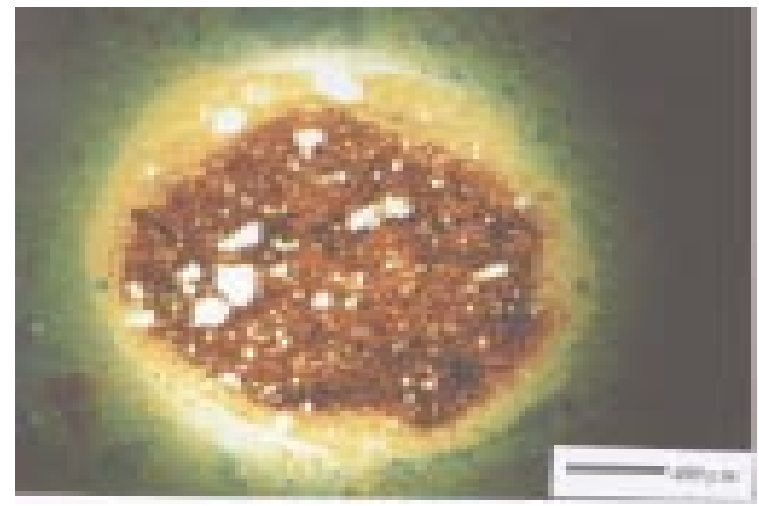

(c)

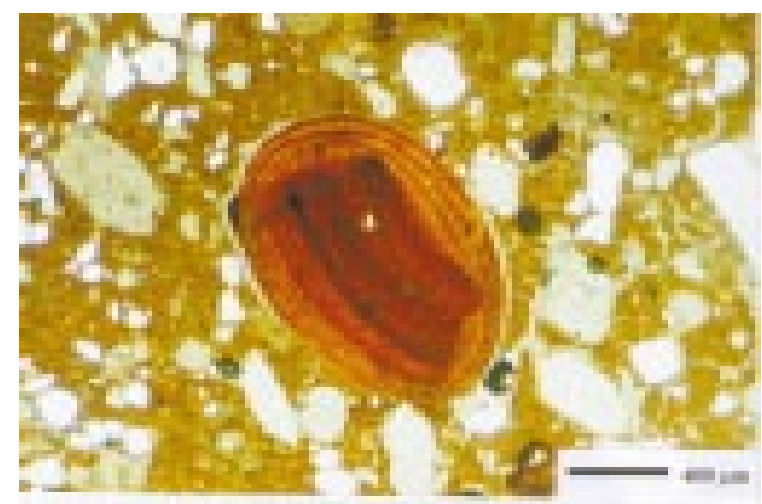

Figura 4. Concreção observada no horizonte BC2 do Cambissolo. Observa-se o aporte de ferro ao redor da estrutura (A), nódulo sesquioxídico do Bi3 do Cambissolo, onde se observam diferentes graus de hidratação dos óxidos de ferro (B), concreção ferro-manganosa da camada de 15-30 cm de um Latossolo Vermelho. Observa-se que a estrutura é constituída por fragmento de concreção recapeado por concentrações $\mathrm{Fe} / \mathrm{Mn}$ posteriores (C).

e no Vertissolo, estas concreções estão recapeadas por novos aportes de ferro, indicando que o processo está em atividade. 


\section{LITERATURA CITADA}

BREWER, R. Fabric and mineral analysis of soils. New York, Robert Krieger, 1976. 482p.

EMPRESA BRASILEIRA DE PESQUISA AGROPECUÁRIA EMBRAPA. Centro Nacional de Pesquisa de Solos. Sistema brasileiro de classificação de solos. Brasília, 1999. 412p.

EMPRESA BRASILEIRA DE PESQUISA AGROPECUÁRIA EMBRAPA. Centro Nacional de Pesquisa de Solos. Manual de métodos de análise de solo. Rio de J aneiro, 1997. 212p.

GERMANIQUE, J.C. Major, trace and rare-earth elements in fourteen GSJ references samples. Determinations by X-ray fluorescence spectrometry and inductively coupled plasma optical emission spectrometry. Geost. Newsl, 18:91-100, 1994.

HALLETT, R.B. \& KYLE, P.R. XRF and INAA determinations of major and trace elements in geological survey of J apan igneous and sedimentary rock standards. Geost. Newsl, 17:127-133, 1993.

HARDEN, J.W.; TAYLOR, E.M.; MCFADDEN, L.D. \& REHEIS, M.C. Calcic, gypsic and siliceous soil chronosequences in arid and semiarid environments. In: NETTLETON, W.D., ed. Ocurrence, characteristics and genesis of carbonate, gypsum and silica accumulations in soils. Madison, Soil Science Society of America, 1991. p.1-16. (Special Publication, 26)

KÄMPF, N. \& SCHWERTMANN, U. The 5-M-NaOH concentration treatment for iron oxides in soils. Clays Clay Miner., 30:401-408, 1982.

KHAN, F.A. \& FENTON, T.E. Secondary iron and manganese distributions and aquic conditions in a Mollisol catena of central I owa. Soil Sci. Soc. Am. J ., 60:546-551, 1996.

McKEAGUE, J.A. \& DAY, J.H.Dithionite and oxalate extractable $\mathrm{Fe}$ and $\mathrm{Al}$ as aids in differentiating various classes of soil. Can. J. Soil Sci., 46:13-22, 1966.

MCKENZIE, R.M. Manganese oxides and hidroxides. In: DIXON, J.B. \& WEED, S.B., eds. Minerals in soil environments. Madison, Soil Science Society of America, 1989. p.439-466.

MCKENZIE, R.M. The surface charge on manganese dioxides. Aust. J. Soil. Res., 19:41-50, 1981.

MEHRA, J.P. \& J ACKSON, M.L. I ron oxides removal from soils and clays by a ditionite-citrate-bicarbonate system buffered with sodium bicarbonate. Clays Clay Miner., 7:317-327, 1960.

OLIVEIRA, C.V.; KER, J.C.; DUARTE, M.N.; CURI, N. \& FONTES, L.E.F. Atributos micromorfológicos de solos do Projeto J aíba, norte de Minas Gerais. R. Bras. Ci. Solo, 24:117-128, 2000.
PHILLIPPE,W.R.; BLEVINS, R.L.;BARNHISEL, R.I \& BAILEY, H.H. Distribution of concretions from selected soils of the inner bluegrass region of Kentucky. Soil Sci. Soc. Am. Proc., 36:171-173, 1972.

RAMANAIDOU, E.; NAHON, D.; DECARREAU, A. \& MELFI, A.J. Hematite and goethite from duricrusts developed by lateritic chemical weathering of precambriam banded iron formations, Minas Gerais, Brazil. Clays Clay Miner., 44:2231, 1996.

ROSS J r., S.J .; FRANZMEIER, D.P. \& ROTH, C.B. Mineralogy and chemistry of manganese oxides in some Indiana soils. Soil Sci. Soc. Am. J ., 40:137-143, 1976.

SANZ, A.; GARCIA-GONZÁLEZ, M.T.; VIZCAYNO, C. \& RODRIGUES, R. Iron-manganese nodules in a semi-arid environment. Aust. J. Soil Res., 34:623-634, 1996.

SCHWERTMANN, U. \& FANNING, D.S. I ron-manganese concretions in hydrosequences of soils in Loess in Bavaria. Soil Sci. Soc. Am. J ., 40:731-738, 1976.

SINGH, B. \& GILKES, R.J . Nature and properties of iron rich gl obules and mottles from some south-west Australian soils. Geoderma, 71:95-120, 1996.

SOARES, M.F. Caracterização química e mineralógica de concreções ferruginosas de al guns sol os brasileiros. Viçosa, Universidade Federal de Viçosa, 1980. 62p. (Tese de Mestrado)

SRIVASTAVA, P.C. \& GUPTA, U.C. Trace elements in crop production. Science, 1996. 356p.

SULLIVAN, L.A. \& KOPPI, A.J . Manganese oxideaccumulations associated with some soils structural pores. I. Morphology, composition and genesis. Aust. J. Soil. Res., 30:409-427, 1992.

TOKASHIKI,Y.; DIXON,J .B. \& GOLDEN, D.C. Manganese oxide analysis in soils by combined $X$-ray diffraction and selective dissolution methods. Soil Sci. Soc. Am. J., 50:1079-1084, 1986.

UZOCHUKWU, G.A. \& DIXON, J.B. Manganese oxide minerals in nodules of two soils of Texas and Alabama. Soil Sci. Soc. Am. J., 50:1358-1363, 1986.

WHITE, G.N. \& DIXON, J.B. Iron and manganese distribution in nodules from a young Texas vertisol. Soil Sci. Soc. Am. J., 60:1254-1262, 1996.

ZHANG, M. \& KARATHANASIS, A.D. Characterization of ironmanganese concretions in Kentucky alfisols with perched water tables. Clays Clay Miner., 45:428-439, 1997. 